\title{
DIVISÃO INTERURBANA NO TRABALHO E USO DO TERRITÓRIO NOS MUNICÍPIOS DE ÁGUAS DE LINDOIA (SP), LINDOIA (SP), SERRA NEGRA (SP), SOCORRO (SP) E MONTE SIÃO (MG)*
}

\author{
Paula Borin
}

Resumo: As pessoas, instituições e empresas, junto com os objetos artificiais e naturais, são um conteúdo do território usado. A região compreendida pelas cidades de Serra Negra (SP), Águas de Lindoia (SP), Lindoia (SP), Socorro (SP) e Monte Sião (MG) apresenta, ainda hoje, situações reveladoras de um uso do território promovido, entre outros atores, por micro, pequenas e médias empresas locais ou regionais. As sucessivas transformações do meio geográfico, em seu conteúdo técnico e político, ofereceram à região a possibilidade de desenvolvimento de especializações territoriais produtivas (turismo, águas minerais engarrafadas e malhas de tricô). Graças a uma profunda divisão interurbana do trabalho, associada à economia de aglomeração relativa a suas especializações, essas pequenas cidades aparecem como pedaços do território que chamam para si atividades afins e complementares, mesmo que concorrentes. Cria-se, também, uma intensa vida de relações entre cidades de diferentes portes, tanto próximas como longínquas.

Palavras-chave: uso do território, especialização territorial produtiva, divisão interurbana do trabalho, meio técnico-científico-informacional

\section{INTERURBAN DIVISION OF WORK AND USE OF TERRITORY IN MUNICIPALITIES OF ÁGUAS DE LINDOIA (SP), LINDOIA (SP), SERRA NEGRA (SP), SOCORRO (SP) E MONTE SIÃO (MG)}

Abstract: The people, institutions and enterprises, together with the artificial and natural objects, are a content of used territory. The land comprises by the towns of Serra Negra (SP), Águas de Lindoia (SP), Lindoia (SP), Socorro (SP) e Monte Sião (MG) present, just now, revealing situations of a promoting use of territory, among others actors, by micro, small and middle local or regional enterprises. The successive transformations of the geographic means, into their political and technical contents, give to the land the possibility of development of territorial productive specializations (tourism, bottling of mineral water and woolen industry). Due to a deep between city division of labor, associated to the economy of relative agglomeration to their specializations, these towns show up like pieces of territory that call for them similar and complementary activities, even though competitors. It creates, also, a intensive life of relations between villages, towns and cities, as near as far.

Keywords: Use of territory, Territorial productive specializations, Between city division of labor, technical-scientific-informational means.

\section{Introdução}

Neste artigo, apresentamos algumas questões e reflexões sobre aspectos da dinâmica urbana de pequenos centros estudados durante nossa pesquisa de mestrado. Nosso objetivo foi o de analisar o conteúdo e funcionamento da divisão interurbana do trabalho da região compreendida pelas cidades de Serra Negra $(\mathrm{SP})$, Águas de Lindoia (SP), Lindoia (SP), Socorro (SP) e Monte Sião (MG), com ênfase em suas especializações territoriais produtivas: turismo, águas minerais engarrafadas e malhas de tricô. São cidades que têm entre 5.000 e 25.000 habitantes.

* Divisão interurbana do trabalho e uso do território nos municípios de Águas de Lindoia (SP), Lindoia (SP), Serra Negra (SP), Socorro (SP) e Monte Sião (MG). Dissertação, Programa de Pós-Graduação em Geografia Humana, do Departamento de Geografia da Faculdade de Filosofia, Letras e Ciências Humanas da Universidade de São Paulo, 2002. Nossa pesquisa de mestrado foi orientada pelo Prof. Dr. Milton Santos e, após sua partida, concluída sob orientação da $\operatorname{Prof}^{\mathrm{a}} \mathrm{Dr}^{\mathrm{a}}$ María Laura Silveira e acolhida generosamente pela professora Maria Adélia de Souza. 
Primeiramente, cabe situar a origem do tema de nossa dissertação dentro do escopo de pesquisa de um projeto de investigação científica mais abrangente, coordenado pelo Professor Milton Santos e pela Professora Maria Laura Silveira, entre 1998 e 2000, intitulado "Empresas territoriais e dinâmicas da formação socioespacial brasileira". Sua proposta de investigar o uso diferenciado do território por diversas firmas, de acordo como o seu tamanho e poder, permitia a escolha de diversas situações a serem analisadas. Entre elas, estavam aquelas reveladoras de um uso do território mais endógeno cujos atores seriam empresas micro, pequenas e médias, "empresas territoriais", menos flexíveis geograficamente, isto é, mais "dependentes das condições gerais de uso da parcela do território em que se instalam", das condições locais ou regionais de produção, circulação, consumo etc.

Desse modo, alguns dos principais aportes teórico-metodológicos que nortearam e fundamentaram nossa análise empírica foram: o conceito de território usado (SANTOS, 1994a, 1998; SANTOS; SILVEIRA, 2001), a partir de sua constituição e seu movimento, como premissa para um olhar geográfico; a divisão territorial do trabalho, permeada pela noção de especialização funcional, como uma possibilidade de pensar o uso do território numa determinada região e rede urbana, e, a noção de divisão interurbana do trabalho. Para compreender como o trabalho se distribui e se reparte utilizamos também os recortes analíticos dos circuitos espaciais de produção e círculos de cooperação.

A categoria central do sistema de conceitos que orientou nossa pesquisa foi a de território usado. As pessoas, instituições e empresas, junto com os objetos artificiais e naturais, são conteúdo do território usado (SANTOS, 1998, p. 3). Nele configura-se um verdadeiro campo de forças, onde a disputa pelo uso do território é promovida, entre outros atores, por empresas de diferentes forças, dimensões e poder.

É importante ressaltar que M. Santos equivale os conceitos de espaço geográfico e território usado, ${ }^{1}$ explicando que "quando quisermos definir qualquer pedaço do território, deveremos levar em conta a interdependência e a inseparabilidade entre materialidade, que inclui a natureza, e o seu uso, que inclui a ação humana, isto é, o trabalho e a política" (SANTOS; SILVEIRA, 2001, p. 247). A materialidade equivale aos sistemas de objetos, artificiais e naturais, e o uso aos sistemas de ações, ambos sistemas formam "um conjunto indissociável, solidário e também contraditório" e não podem ser considerados isoladamente, "mas como o quadro único no qual a história se dá" (SANTOS, 1996, p. 51).

Ao preocuparmo-nos com o território e seu uso, somos levados a considerar o fenômeno da técnica, uma vez que as técnicas aparecem como autorizações para o fazer (SANTOS, 1996, p. 45; FRIEDMANN, 1968). Os sistemas técnicos autorizam, a cada época, uma determinada distribuição e reprodução dos objetos e ações, criadora de densidades e rarefações. Esse fenômeno é a divisão territorial do trabalho. Com as técnicas e a política o trabalho realiza-se e se divide. Daí nossa opção de pensar o uso do território via divisão territorial do trabalho.

\footnotetext{
${ }^{1}$ M. Santos (1994a, p. 15) já falava em território usado, em 1994, quando escreveu: "é o uso do território, e não o território em si mesmo, que faz dele objeto de análise social".
} 


\section{A divisão territorial do trabalho: uma possibilidade de pensar o uso do território}

Os conceitos de divisão territorial do trabalho e divisão social do trabalho estão fortemente imbricados.

Dentro das Ciências Sociais, o fenômeno divisão social do trabalho foi amplamente estudado e teorizado. Em 1893, E. Durkheim dedicou-se ao tema em seu livro Da Divisão Social do Trabalho. Na introdução do livro destaca que trata-se de um fenômeno social encontrado desde a antiguidade e considera que, apesar de vários pensadores reconhecerem sua importância, "foi Adam Smith o primeiro a tentar teorizá-la" (DURKHEIM, 1995, p. 1). ${ }^{2}$ Coloca, também, como tal fenômeno se intensificava com a consolidação do capitalismo e desenvolvimento da indústria moderna da época. ${ }^{3}$

Nesse mesmo contexto histórico, Marx (O capital, capítulo XII, 1867) também adotou a noção de divisão do trabalho, analisando-a no interior da manufatura e considerando sua importância ao funcionamento do modo de produção capitalista.

São sucessivas e superpostas divisões do trabalho - sistemas temporais e os respectivos sistemas técnicos e meios geográficos - que constroem a história. 0 movimento das divisões territoriais do trabalho é a expressão do processo de

\footnotetext{
2 Em A riqueza das nações (1776), a ideia de divisão do trabalho é analisada.

3 "Hoje, esse fenômeno generalizou-se a tal ponto que salta aos olhos de todos. Não há mais ilusão quanto às tendências de nossa indústria moderna; ela vai cada vez mais no sentido dos mecanismos poderosos, dos grandes agrupamentos de forças e capitais e, por conseguinte, da extrema divisão do trabalho" (DURKHEIM, 1995, p. 1)
}

totalização: que dá sentido à distribuição e ao funcionamento dos objetos e das ações (intencionalidades) em cada pedaço de tempo.

Essa repartição do trabalho é dada pela distribuição tanto do trabalho vivo como do trabalho morto e dos recursos naturais, ou seja, pelo uso do território. Desse modo, a divisão do trabalho expressa-se como divisão territorial do trabalho:

A divisão social do trabalho é frequentemente considerada como a repartição (ou no Mundo, ou no Lugar) do trabalho vivo. Essa distribuição, vista através da localização dos seus diversos elementos, é chamada de divisão territorial do trabalho. Essas duas formas de considerar a divisão do trabalho são complementares e interdependentes. Esse enfoque, todavia, não é suficiente, se não levarmos em conta que, além da divisão do trabalho vivo, há uma divisão territorial do trabalho morto (SANTOS, 1996, p. 112).

A divisão territorial do trabalho é motor de especializações produtivas, que por sua vez alimentam o seu aprofundamento. A especialização econômica é decorrente, entre outros fatores, da divisão social do trabalho, que "movida pela produção, atribui, a cada movimento, um novo conteúdo e uma nova função aos lugares" (SANTOS, 1996, p. 105).

Graças aos avanços técnicos e à sua incorporação ao meio geográfico - como a constituição de um meio técnico-científico-informacional (rede de transportes e comunicações, serviços como saúde e educação em todos os graus etc.) -, hoje, torna-se possível a repartição de tarefas entre vários lugares e áreas. Muitas cidades desempenham funções específicas e há um alargamento da vida de relações interurbanas. Com uma urbanização 
acentuada e diversificada, intensifica-se a complementaridade entre as cidades, definindo-se novos recortes e funções regionais.

A especialização territorial aparece sob diferentes formas e em diferentes lugares. Podemos encontrar especializações engendradas por grandes corporações, implicando muitas vezes numa guerra de lugares; outras que têm como característica o desenvolvimento de atividades ultra modernas e encontramos também as promovidas por empresas locais ou regionais.

Para R. L. Corrêa (1999, p. 48), a especialização produtiva torna-se, no período atual, uma das duas maiores possibilidades de refuncionalização das pequenas cidades, face o impacto da globalização sobre a rede urbana em todos os seus níveis:

A segunda possibilidade diz respeito à transformação do pequeno núcleo a partir de novas atividades, induzidas de fora ou criadas internamente, que conferem uma especialização produtiva ao núcleo preexistente, inserindo-o diferentemente na rede urbana, introduzindo nela uma mais complexa divisão territorial do trabalho. As especializações produtivas, por outro lado, conferem aos núcleos urbanos uma singularidade funcional, entendida como características que são simultaneamente de diferenciação no âmbito da economia global e de integração a esta mesma economia. A centralidade, ao que tudo indica, pode ser ampliada (CORRÊA, 1999, p. 50).

Há que se considerar, também, para a compreensão das relações interurbanas, dos novos conteúdos da rede urbana e dos papéis regionais o par dialético densidade e mobilidade, cujo motor são outros pares: estado-mercado, novo-velho, externo-interno, como sugere M. L. Silveira (2000).
A noção de densidade remete-se à de especialização produtiva por dois motivos. A especialização produtiva só se realiza em parcelas do território onde há determinadas densidades técnicas (por exemplo, sistemas de engenharia), normativas, informacionais, comunicacionais que permitem que 0 trabalho seja repartido. E as regiões e os lugares especializados concentram sistemas de objetos e ações particulares às suas especialidades, revelando verdadeiras densidades, ou seja, economias de aglomeração.

Segundo G. Benko (1999, p. 41), um dos primeiros autores a tratar da noção de economia de aglomeração é Wilhem Launhardt, em 1900 e, posteriormente, Harold Hotelling (1929). Este estudioso defende os efeitos positivos de aglomeração, analisando-os em dois aspectos: economias de aglomeração internas ao ramo de atividade (proximidade entre fornecedores, distribuidores, serviços de suporte etc.) e efeitos de proximidade externos ao ramo de atividade.

Atualmente, podemos dizer que a concentração de atividades idênticas e afins em uma mesma porção do território continua ocorrendo, mas as economias de aglomeração se transformaram e ganharam complexidade. Seus efeitos econômicos, sociais e políticos continuam sendo relevantes e estudados por diferentes ciências. A partir de um olhar geográfico e contemporâneo, M. Santos e M. L. Silveira (2001) apontam alguns aspectos importantes decorrentes das economias de aglomeração.

Em primeiro lugar, a acumulação de atividades semelhantes ou complementares numa área cria uma espécie de efeito de massa, uma nova economia de escala que acaba 
por reduzir os custos globais e individuais. Em segundo lugar, a proximidade entre tais atividades produz um efeito de vizinhança que implica facilitar a difusão de informações gerais e específicas não apenas ligadas aos processos mas interessando também ao próprio funcionamento do mercado, o que representa importante vantagem comparativa (SANTOS; SILVEIRA, 2001, p. 299).

As lógicas contrastantes entre as empresas locais que concorrem entre si existem, mas, ao mesmo tempo, a especialização produtiva, implicando que empresas de um mesmo ramo instalem-se e convivam num mesmo local, proporciona vantagens. As tarefas especializadas além de reduzirem "os respectivos custos unitários, aumentando a produtividade e a rentabilidade de cada agente individual", pela divisão interurbana do trabalho decorrente, fortalecem o conjunto de cidades (SANTOS, 1996, p. 227).

As especializações são tanto resultado como promotoras de divisões interurbanas do trabalho. É, também, por isso que especialização produtiva, cooperação e circulação são indissociáveis. E as densidades só se constituem pela presença da fluidez.

Analisando a divisão interurbana do trabalho, de um lado encontra-se a especialização produtiva das cidades, como princípio da repartição e da particularidade, da individualização; de outro está a necessidade de circulação e cooperação, que são os fluxos, as solidariedades e o movimento, ou seja, tudo o que promove a interação, a complementaridade e que permite, ao mesmo tempo, mais especialização.
Considerando os novos conteúdos das atividades produtivas, a distribuição assume cada vez maior importância, sobretudo na relação entre produção e consumo capitalista. R. L. Corrêa (1997, p. 18) coloca que o papel da distribuição torna-se crucial na sociedade e em sua organização espacial.

A organização espacial da distribuição que emerge, fundamentada na divisão social e territorial do trabalho, na existência de uma massa predominantemente assalariada, e na articulação entre diferentes áreas produtoras, tem como locais as cidades que se interligam através do comércio atacadista, varejista e dos serviços (CORRÊA, 1997, p. 18).

A circulação, então, assume um papel de base para a cooperação. Quanto mais os lugares e regiões se especializam mais a cooperação se faz necessária. Para entendermos esse fenômeno atual da circulação e da cooperação recorremos à noção de circuitos espaciais da produção e círculos de cooperação. Os circuitos produtivos articulam as várias etapas da produção pelas quais percorre o produto. São definidos pela circulação de produtos, isto é, de matéria. Os círculos de cooperação, sendo formas de regulação do processo produtivo e assegurando a realização do capital, associam aos fluxos materiais outros fluxos, como os imateriais: de capital, de informações, de mensagens, de ordens etc. (SANTOS, 1994b, p. 128).

Analiticamente, cada circuito espacial possui uma divisão territorial do trabalho própria contudo, nas cidades, no conjunto de cidades, na região eles se encontram, intercruzam-se e na coexistência se concretizam, resultando numa divisão interurbana do trabalho. 


\section{Da divisão territorial do trabalho à periodização}

Ao considerarmos a divisão territorial do trabalho como expressão do uso do território, estamos admitindo-a como uma totalidade. Mas uma totalidade não é uma realidade estática, a cada mudança de um de seus elementos produz-se uma transformação que resulta numa totalidade nova, na qual tanto as partes como o todo não são mais os mesmos que os do momento anterior.

[...] o todo somente pode ser conhecido através do conhecimento das partes e as partes somente podem ser conhecidas através do conhecimento do todo. Essas duas verdades são, porém, parciais. Para se alcançar a verdade total, é necessário reconhecer o movimento conjunto do todo e das partes, através do processo de totalização (SANTOS, 1996, p. 96).

O território não é utilizado igualmente nos diferentes momentos de tempo. Daí decorre a necessidade de identificar quais as características significativas que explicam a coerência de cada período.

Os períodos se compõem de regularidades (padrões) que, num determinado momento, entram em crise dando caminho ao estabelecimento de uma nova época.

[...] períodos são pedaços de tempo definidos por características que interagem e asseguram o movimento do todo. Mas essa interação se faz segundo um controle que assegura uma reprodução ordenada das características mais gerais, isto é, segundo uma organização. É a falência desta última, açoitada por uma evolução mais brutal, de um ou de diversos fatores, que desmantela a harmonia do conjunto, determina a ruptura e permite dizer que se entrou em um novo período (SANTOS; SILVEIRA, 2001, p. 24).

É com a periodização que podemos explicar a história do uso do território na região pesquisada. As periodizações podem ser muitas, variando de acordo com o fenômeno que se quer interpretar. Daí nossa proposta de entender como se desenharam na região sucessivas divisões interurbanas do trabalho, associado-as ao surgimento e desenvolvimento de suas especializações. Periodizar é fundamental para o entendimento do presente, que acumula tempos passados e, por conseguinte, divisões territoriais do trabalho superpostas.

\section{As especializações produtivas da região: uma breve periodização}

As sucessivas transformações do meio geográfico, em seu conteúdo técnico e político, ofereceram à região a possibilidade de desenvolvimento de especializações empreendidas sobretudo por atores locais.

Temos um primeiro momento, que se inicia com as primeiras ocupações da região e o nascimento de pequenas aglomerações, passando por um período de especialização agrícola até o desenvolvimento da mais antiga especialização territorial da região: o turismo termal.

A região da Serra da Mantiqueira onde atualmente situa-se o município de Lindoia e Águas de Lindoia tornava-se, desde 1728, uma área de passagem e pouso de tropas $^{4}$ para depois abrigar uma ocupação

\footnotetext{
4 "Em 1728, devido às propriedades já conhecidas das Águas de Lindoia, então Águas Quentes, afluíram para este local moradores de outros Municípios, como Santos, Atibaia e Bragança. Foi,
} 
mais sedentária. Para a gênese da ocupação desta porção da Serra da Mantiqueira é necessário considerar a sua condição de espaço de circulação, situação coerente com - contexto paulista da época colonial. A ocupação mais efetiva da região de Serra Negra, Lindoia a Socorro, ocorreu durante entre fins do século XVIII e primeira metade do século XIX. ${ }^{5}$ Serra Negra foi fundada em 1828, sendo que no ano seguinte, 1829, fundava-se Socorro. Vinte anos mais tarde nasce oficialmente Monte Sião, em 1849. Formava-se, assim, um conjunto de povoados que serão, graças à evolução do meio geográfico, cada vez mais contíguos. Mais tarde, alguns dos povoados irão transformar-se em sedes de municípios ou distritos de municípios maiores.

Com o desenvolvimento da cafeicultura em larga escala, no final do século XIX, a região passa de um uso do território baseado na policultura para 0 predomínio da monocultura e de uma economia de subsistência - associada a um mercado mais contíguo e limitado - para uma economia baseada na produção para o grande mercado, externo à região e ao país. A presença de um meio técnico, mesmo que seletiva, e o desenvolvimento da cafeicultura impulsionava a vida dos pequenos povoados, introduzindo-lhe novas qualidades. A divisão

ainda, devido ao acesso às Minas de Goiás e constantes pousadas de tropas que surgiu este aglomerado" (IBGE, 1957a, p. 28). Posterior aos pousos de bandeira, o pouso de tropas (de burros principalmente) ganha importância a partir do século XVIII (MORAES, 1935, p. 81-82).

${ }^{5}$ Para J. D. Silveira (1946, p. 58-59), os núcleos que se formaram nessa região, entre eles Serra Negra, Socorro, foram povoados "como natural fenômeno de expansão de uma sociedade", fruto do deslocamento de desbravadores oriundos de áreas contíguas como Atibaia ou Bragança. Segundo o autor, os núcleos viviam "de uma atividade puramente local dentro de uma economia sem comércio externo" (SILVEIRA, 1946, p. 60). do trabalho intensificava-se, tanto local como regionalmente.

A vida urbana se animava, fruto de uma nova materialidade que se construía e de um conjunto de novas ações que se desenvolve no interior dos núcleos e distritos municipais. Contudo, os lugarejos dinamizavam-se em função do campo, servindo "às zonas de produção" (SANTOS; SILVEIRA, 2001, p. 34).

Nas primeiras décadas do século $X X$, a região inseria-se, aos poucos, numa divisão do trabalho que se complexizava. Com o excedente agrícola produzido gerava-se riqueza para os novos consumos, demandando uma diversificação das atividades e do sistema de objetos urbanos. Para atender as novas demandas internas, ampliavam-se os intercâmbios entre pontos contíguos e mais distantes, graças também aos novos sistemas técnicos disponíveis, tais como a mecanização da produção e a motorização do território.

A urbanização de São Paulo e de algumas outras cidades determinavam uma nova divisão territorial do trabalho. Com a formação de um embrião da Região Concentrada (SANTOS; RIBEIRO, 1979), da qual nossa região participava muito perifericamente, uma nova especialização produtiva regional passa a ser impulsionada pelo crescimento do mercado interno.

Nesse momento a região gradativamente assumia um novo papel: o de centro de cura e turismo. ${ }^{6}$ Esta função se

\footnotetext{
${ }^{6}$ Desde o século XIX, ganhava ênfase a produção e difusão de um saber científico que investigava os efeitos terapêuticos das águas. Já no final do século, havia cátedras de hidrologia médica nas principais universidades europeias (SIMÕES, 1986, p. 4 apud SILVESTRE，1995, p. 30; MOURÃO,
} 
consolidaria sobretudo durante as décadas de 1930 e 1940, com o auge do termalismo e do turismo de jogo. Frente à expansão do consumo interno, estas novas funções relacionavam-se às novas necessidades criadas e difundidas, sobretudo entre as elites endinheiradas.

A construção das Thermas de Lindoia, iniciada em 1910, marcaria o início desta nova fase. Nas décadas seguintes, o turismo se difundiria seletivamente para algumas localidades vizinhas, em especial Serra Negra.

Os anos de 1930 e 1940 são considerados por J. Langenbuch (1977, p. 42) como o período dos "grandes hotéis", onde era frequente a presença de jogos de azar. Muitos deles, construídos ou em funcionamento desde as primeiras décadas do século $X X$, tiveram neste intervalo de tempo uma fase áurea.

Neste período surge, também, o embrião de uma nova especialização produtiva: o engarrafamento de água mineral. Alguns proprietários de hotéis, localizados próximos às fontes de água mineral, iniciam a extração e o envasamento das águas de suas propriedades para utilizálas nos tratamentos medicinais de seus hóspedes. A indústria do envasamento nascia, nesse momento, atendendo ao objetivo de prolongar a cura dos doentes (frequentadores dos balneários) em suas casas; estes, amiúde, se tornavam consumidores habituais. Com 0 desenvolvimento dos transportes, a ideia de engarrafar foi se generalizando e o consumo

1997, p. 232-233). Nas primeiras décadas do século $X X$, foram criados no Brasil cursos de crenoterapia, tanto no Rio de Janeiro como em Belo Horizonte, causa e consequência da expansão do termalismo. doméstico ampliou-se, potencializando não apenas o valor medicinal das águas mas o seu valor comercial (NUNES et al., 1999). Assim, ampliava-se o consumo da água mineral além da fonte.

Em um segundo período, que se inicia no segundo pós-guerra, o turismo refuncionaliza-se ao mesmo tempo em que se consolida como a grande identidade da região. A irradiação do meio técnico promovia mudanças tanto na zona rural, a mais populosa, como na urbana. Trata-se de um período de transição.

O turismo baseado no tratamento de saúde e nos "jogos de azar" era afetado por duas novas conjunturas que se delinearam a partir da segunda metade da década de 1940: o fechamento dos cassinos e o início da "era dos antibióticos", ou seja, a difusão da nova medicina fortemente vinculada ao comércio de remédios alopáticos. Atingia-se, assim, os dois pilares do tradicional uso turístico da região.

Os lugares especializados no turismo do jogo e no termalismo não mudaram imediata e repentinamente frente aos novos conteúdos normativos, técnicos e informativos que afetavam negativamente as suas atividades. A propagação das informações era relativamente lenta e o lugar ainda podia oferecer resistência no sentido de preservar seu uso tradicional. Todavia este tipo de turismo sofria gradativamente um forte impacto, deixando, ao final do período, de ser o predominante na região.

Mas, apesar do momento de crise, a especialização turística confirma-se graças a um movimento de refuncionalização do turismo local e à criação de novos objetos adequados às novas funções. 
No Brasil, a promulgação das leis trabalhistas (1943), a motorização familiar (indústria automobilística), a difusão das formas de acesso, melhoramentos nas rodovias e construção de novas estradas, a ampliação do consumo no mercado interno, a emergência de uma classe média, a melhoria da massa salarial de um conjunto de categorias profissionais contribuíam para a banalização do turismo e para o crescimento do turismo nacional, estimulando a concorrência entre os lugares turísticos. O tempo de improdutividade, criado graças a novas normas mas também a novas técnicas, torna-se uma das bases da produtividade dos espaços turísticos (SILVEIRA, 1997, p. 40).

Paulatinamente, as rodovias, principalmente no Estado de São Paulo, colaboravam para uma expansão mais contígua do meio técnico, aproximando a região de novos mercados consumidores internos e, assim, atribuindo-lhe novos papéis na divisão do trabalho em curso.

Em torno da atividade turística da região formava-se uma economia complementar, representada pelas engarrafadoras de águas minerais; ${ }^{7}$ pelo comércio e artesanato que tinham nos turistas seus principais consumidores $e$, também, compunham as ofertas turísticas da região.

Segundo E. Nunes et al. (1999), de um modo geral, os primeiros "empreendedores" do engarrafamento de águas no Brasil foram proprietários locais. R. L. Corrêa (1999, p. 50) coloca que "as

7 Neste contexto, surge uma das empresas pioneiras no engarrafamento comercial de águas minerais: o Lindoiano Hotel Fontes Radioativas Ltda., fundada em 1951. Em meados da década de 1950 todos os municípios da região tinham engarrafadoras. especializações produtivas podem também ser criações das elites locais que necessitam encontrar outras atividades que lhes permitam manter-se como tais". Estas duas situações estiveram presentes nas origens da nova especialização produtiva que começava a ganhar força na região: a indústria extrativa de águas minerais.

Com os primórdios do meio técnico-científico-informacional, a atividade turística refuncionaliza-se mais uma vez e a produção industrial começa a ganhar impulso. Cresce a produção de águas minerais e moderniza-se gradativamente seu processo produtivo.

A densificação e modernização do sistema viário, facilitando o acesso aos pontos venda; a inovação em embalagens e a concentração de consumidores compunham um quadro que estimulava a expansão do comércio de águas minerais. Em Lindoia, havia 1 engarrafadora na década de 1950 e, neste momento, o número elevava-se para 6 . Surgiram neste período as seguintes empresas locais: Lindoyana de Águas Minerais Ltda., fabricante da Genuína Lindoya, fundada em 1965 (Lindoia); Empresa de Mineração Mantovani Ltda., fabricante da Lyndoia Vida, fundada em 1968 (Lindoia); Empresa Mineradora Serra Negra Ltda., fabricante da Serra Negra Saúde, fundada em 1973 (Serra Negra); entre outras. Em Serra Negra havia registro de pelo menos duas engarrafadoras.

Paralelamente, surge, a partir de uma atividade artesanal, a fabricação de malhas de tricô. O aproveitamento de um saber local, uma prática artesanal tradicional, tornava-se o embrião de uma nova e importante especialização produtiva. 
Aspectos internos e externos à região contribuíram para o seu desenvolvimento. Entre eles, internamente, a atividade turística contribuía com a geração de um mercado consumidor de artigos artesanais e havia uma potencialidade para o consumo in situ. Cabe destacar que, em 1971, era elaborado o primeiro plano para o Circuito das Águas, agora uma região reconhecida oficialmente pelo Governo do Estado e objeto de planejamento estatal. Esta região agrupava os municípios de Atibaia, Bragança Paulista, Amparo, Socorro, Serra Negra, Lindoia, Águas de Lindoia e Monte Alegre do Sul.

Quanto ao vetor externo, a partir da segunda metade da década de 1960, a empresa Lanofix, multinacional japonesa de máquinas têxteis manuais com representantes na cidade de São Paulo, fez uma forte campanha de vendas tanto na cidade de Monte Sião como na de Socorro. ${ }^{8}$ Concomitantemente, num contexto nacional e mundial, a ampliação da produção e utilização de fibras artificiais e sintéticas na confecção de malhas, e consequentemente maior disponibilidade de matéria-prima, foi fundamental para o processo de industrialização dessa atividade artesanal.

Gradativamente, o crescimento dessa atividade fabril trazia consigo demandas por infraestruturas, comércio e serviços específicos essenciais a sua sustentação. Construía-se, assim, as bases de uma economia de aglomeração, ainda embrionária, que passará a ser também um atrativo territorial, trazendo para a região novas iniciativas e atividades afins. Desse modo, já na primeira metade de 1980, havia

8 Estes centros urbanos participavam residualmente das especializações regionais do turismo e do engarrafamento de águas minerais. depósitos de fios em Monte Sião, Serra Negra, Socorro e Amparo, possibilitando vendas a prazo para uma boa quantidade de pequenas empresas.

No final deste período, com a internacionalização da economia nacional, a chegada mais maciça das multinacionais trouxe impactos diversos sobre a região: a multinacional Van Leer, produtora de embalagens plásticas, consegue ampliar seu mercado consumidor com as empresas de engarrafamento de água mineral; a Lanofix, difunde-se na região colaborando para a mecanização de uma produção artesanal; algumas multinacionais, como a Volkswagen, procuravam a região para a realização de convenções.

Os vetores de internacionalização da economia atingiam a região, trazendo novos conteúdos para suas especializações. No caso das engarrafadoras, algumas conseguiram absorver as inovações das embalagens plásticas, aumentaram suas vendas e, mais tarde, puderam investir em seus próprios equipamentos de embalagens. No caso do turismo de convenções, depois de alguns anos, muitas empresas multinacionais deixaram de procurar os hotéis da região para suas convenções. Este acontecimento, apesar de seu forte impacto negativo, não significou uma derrocada do turismo de convenções na região, porque seus hotéis passaram a acolher novos eventos tais como congressos científicos, reuniões de associações ou instituições etc. $E$ a produção de malhas se mecanizava, construindo as bases para sua modernização no período seguinte.

$$
\text { O aprofundamento da divisão do }
$$
trabalho no centro da Região Concentrada - 
graças ao adensamento da população; às maiores capacidades de circulação de bens, pessoas, informação, dinheiro; à ampliação do consumo - colaborou para que a região fundasse sua economia no mercado interno.

Segundo W. Santos (1989, p. 106107), o Circuito das Águas seria uma das áreas da região de Campinas que está numa situação intermediária entre a concentração e a dispersão, "uma vez que apresentam alguns sub-eixos e médios pontos de concentração em estradas e cruzamentos viários relativamente importantes para o contexto regional". Talvez, por ser uma região periférica no interior de uma região moderna, os atores locais promotores das especializações territoriais produtivas (turismo, águas minerais engarrafadas e malhas de tricô) conseguiram beneficiar-se das novas potencialidades de circulação e cooperação produtiva, ainda que menos do que os atores hegemônicos e numa escala muito menor.

\section{Uso do território e dinâmica interurbana da região}

As possibilidades de repartição de tarefas entre vários lugares e áreas aprofundaram-se graças aos avanços técnicos, sobretudo aqueles ligados à informatização e a circulação de informações, e à sua incorporação ao meio geográfico. Intensificam-se as especializações territoriais e há um alargamento da vida de relações interurbanas.

Em um quadro geral, no início do século XXI, a divisão interurbana da região caracteriza-se pela presença de cidades com populações entre 5 e 20 mil habitantes. ${ }^{9}$

As malharias, presentes em todas as cidades da região, concentram-se em maior número e diversidade de topologias em Monte Sião, que se destaca como o grande centro regional de fabricação e comercialização de malhas de tricô. Em 2008, havia no município cerca de 1.200 malharias.

Águas de Lindoia, além de um significativo número de malharias (localizadas principalmente na rodovia que a liga ao município mineiro), fundamenta sua economia nas atividades turísticas, possuindo um grande e tradicional parque hoteleiro, e uma forte especialização em turismo de eventos. Serra Negra acrescenta à sua função turística a de polo comercializador de malhas. Águas de Lindoia e Serra Negra concentram a maior parte da rede hoteleira regional. Socorro, com cerca de 400 malharias em 2002, começava a se destacar pelo turismo de aventura, possuindo já hotéis especializados nestas práticas de lazer e esporte.

\begin{tabular}{|c|c|c|}
\hline Município & 1991 & 2000 \\
\hline Águas de Lindoia & 11.966 & 16.190 \\
\hline Urbana & 11.359 & 15.463 \\
\hline Taxa de urbanização & 94,93 & 95,51 \\
\hline Lindoia & 4.118 & 5.331 \\
\hline Urbana & 3.541 & 4.716 \\
\hline Taxa de urbanização & 85,99 & 88,46 \\
\hline Serra Negra & 21.704 & 23.851 \\
\hline Urbana & 17.431 & 20.612 \\
\hline Taxa de urbanização & 80,31 & 86,42 \\
\hline Socorro & 30.763 & 32.704 \\
\hline Urbana & 16.999 & 20.980 \\
\hline Taxa de urbanização & 55,26 & 64,15 \\
\hline Monte Sião & 17.328 & 18.195 \\
\hline Urbana & 9.111 & 12.729 \\
\hline Taxa de urbanização & 52,58 & 69,96 \\
\hline
\end{tabular}

Fonte: IBGE, Censo Demográficos de 1991 e 2000. 
Lindoia

destaca-se

no

engarrafamento de águas minerais, atividade que emprega cerca de $70 \%$ da população, sendo aproximadamente $90 \%$ dos empregados das engarrafadoras residentes no município e cidades vizinhas (pesquisa de campo realizada em 2001). Segundo dados de 1994, Lindoia era a maior produtora de água envasada no Brasil, sua participação na produção nacional estava em torno de 6,5\%. Serra Negra e Águas de Lindoia aparecem também como importantes cidades industrializadoras no panorama nacional do setor, junto com Campos de Jordão e Poá (Gazeta Mercantil, 1997, p. 33). Em 2000 e 2001, três empresas de Lindoia continuavam entre as principais empresas engarrafadoras de água mineral do Brasil: Água Lindoya Genuína, Lindoia Bio-Leve e Lindoya Vida (Sumário Mineral, 2001; 2002). A Lindoya Genuína e a Lindoya Vida são de empresas tradicionais de Lindoia, sua história começa com a iniciativa de moradores da localidade. A Bio-Leve é uma empresa nacional que chegou à região no fim da década de 1990 .

A localização, mesmo que historicamente periférica, dessas cidades dentro da Região Concentrada foi fundamental para o surgimento e consolidação de suas especializações territoriais, visto que o aglomerado metropolitano Campinas-São Paulo e seu entorno, ainda neste momento, participa do abastecimento da região tanto em relação ao consumo consumptivo como produtivo e também aparece como um dos mais importantes mercados consumidores dos produtos e serviços locais, junto com interior paulista e Rio de Janeiro.

O consumo assume um novo papel neste período e ganha volumes jamais vistos.
O aumento da população urbana no país e nos grandes centros participa da explicação deste fenômeno, assim como o crescente assédio das propagandas no cotidiano das pessoas.

Nesse contexto, as especializações produtivas beneficiam-se deste crescimento do consumo. Amplia-se o consumo de água mineral enormemente, principalmente nos anos 1990. A volubilidade da moda de certa forma contribui para um consumo mais descartável de roupas. E, o turismo torna-se cada vez mais um novo objeto de consumo (BERTONCELLO, 1992, p. 1). Para L. Ferrara (1996, p. 21), "na nossa economia global já não há tempo livre, mas a necessidade de empregar, através do deslocamento no espaço, o dinheiro poupado ao tempo de trabalho".

Todavia não podemos tratar o consumo como uma ação homogênea. Existem vários tipos de consumo, refletindo a própria diversidade social e territorial. Reconhecer suas diferentes manifestações é fundamental para compreender as especializações produtivas na região. A variedade de tipos de consumo relaciona-se principalmente aos níveis de renda e ao poder de compra da população e, de certa forma, ao revelar uma segmentação do mercado, garante a coexistência de empresas de diferentes portes.

Algumas engarrafadoras, assumindo os custos de embalagens mais sofisticadas, optam pelo mercado mais lucrativo dos descartáveis, disputando o mercado com grandes corporações. Outras passaram a dedicar-se sobretudo ao comércio dos galões de 10 e 20 litros, um segmento do mercado que não interessa, até o momento, a 
multinacionais como a Coca-Cola ou a Nestlé, entre outras.

O turismo de convenções consolidase e vários hotéis reafirmam sua opção por este mercado. Ao mesmo tempo, outras empresas procuram diferentes segmentos do mercado turístico, como o turismo rural em Serra Negra e o de aventura em Socorro.

A busca por uma diversificação
associada ao trabalho conjunto e complementar revela estratégias territoriais horizontais muito interessantes. Nesse sentido, é muito significativa a iniciativa da Política para Congressos, promovida por um site importante de Águas de Lindoia.

Os hotéis sede e de apoio ao congresso atuam de forma conjunta, atendendo às necessidades dos eventos quanto à infraestrutura, adequação de ambientes, tarifas diferenciadas, serviços e hospedagem. Com a experiência de quem faz mais de 1.000 eventos por ano, Águas de Lindoia realiza eventos há várias décadas e conta com profissionais especializados para darem suporte técnico às empresas (www.portalaguasdelindaia, acesso em: 28 ago. 2011).

Do ponto de vista das relações interurbanas, os eventos promovidos por uma prefeitura ou por entidades particulares (uma feira, uma exposição, um encontro de maior porte) produzem reflexos na dinâmica econômica e empresarial de toda região. Há, também, relações horizontais entre as próprias empresas locais e regionais. O Monte Real Resort, maior hotel de Águas de Lindoia, comporta até 6.432 pessoas em suas salas e auditórios e 580 hóspedes em seus apartamentos. Logo, se um evento com aproximadamente 6.000 participantes é realizado neste hotel, cria-se uma demanda de hóspedes para outros estabelecimentos concorrentes do próprio município e da região. A capacidade máxima de hospedagem em Águas de Lindoia está em torno de 5.000 pessoas enquanto que as mais de 50 salas de seus hotéis abrigam até 11.000 pessoas simultaneamente.

Durante a década de 1990, muitas malharias, sobretudo as sediadas em Monte Sião, conhecem um período de modernização do processo produtivo através da introdução dos teares computadorizados baseados na microeletrônica, ${ }^{10}$ investem na utilização de fios mais sofisticados e no design das peças. Novas topologias e formas de organização surgem articulando empresas de diferentes portes e níveis técnicos. Esses fatores, entre outros, ajudaram no enfrentamento da crise decorrente de invernos poucos rigorosos e da concorrência com os produtos têxteis chineses (FUINI, 2006, p. 122-124).

Em sua dissertação sobre Monte Sião e Jacutinga, L. L. Fuini (2006, p. 129) revela que, entre as principais vantagens locacionais do Circuito das Malhas mencionadas por proprietários de malharias, aparecem em primeiro lugar "a tradição e o prestígio do lugar", seguidos por "qualidade da mão de obra", "proximidade do mercado consumidor", "relações familiares" (o saber fazer), "presença de fornecedores de maquinário e matérias-primas".

A economia de aglomeração gerada pelas diferentes especializações, na qual se

10 Número de teares microeletrônicos compradas
por empresas de Monte Sião - 1993-2000
\begin{tabular}{ll}
\hline Ano & Número de teares \\
\hline 1993 & 4 \\
\hline 1995 & 20 \\
\hline 1997 & 100 \\
\hline 1999 & 500 \\
\hline 2000 & +ou- 1.000 \\
\hline
\end{tabular}

Fonte: ACIMS (2001). 
inclui uma rica densidade comunicacional, aprofunda o conteúdo do acontecer homólogo na região.

Analisar o conteúdo e funcionamento da divisão interurbana do trabalho da região compreendida pelas cidades de Serra Negra $(\mathrm{SP})$, Águas de Lindoia (SP), Lindoia (SP), Socorro (SP) e Monte Sião (MG) permitiu-nos encontrar situações empíricas contemporâneas reveladoras de um uso do território fortemente fundado na existência de um acontecer homólogo, historicamente construído.

Um uso do território revelador de horizontalidades, formada pelo trabalho coletivo - solidário e conflitivo - que "é, também, copresença num espaço contínuo, criando 0 cotidiano da contiguidade" (SANTOS, 1996, p. 268).

Essa interdependência horizontal é grande não apenas em relação às empresas protagonistas das especializações produtivas, como do ponto de vista da vida de relações cotidianas dos seus habitantes. Cria-se, assim, intensa vida de relações onde várias cidades atuam conjuntamente.

Ao estudarmos este conjunto de pequenas cidades, preocuparmo-nos em dar conta da "complexidade do estudo do mais pequeno". Como nos alerta M. Santos (1985, p. 3), "quanto mais pequeno o lugar examinado, tanto maior o número de níveis de determinações externas que incidem sobre ele".

Frente à maior profusão de vetores externos incidindo sobre os lugares, consolida-se, ao mesmo tempo, uma interdependência horizontal entre as cidades, alicerçada na existência de um acontecer homólogo feito de atividades afins $e$ complementares, mesmo que concorrentes.

\section{Referências bibliográficas}

CORRÊA, R. L. Globalização e reestruturação da rede urbana: uma nota sobre as pequenas cidades. Território, Laget/UFRJ, Rio de Janeiro: Garamond, n. 6, p. 43-53, jan./jun. 1999.

Trajetórias geográficas. Rio de Janeiro:Bertrand Brasil, 1997.

BENKO, G. A ciência regional. Oeiras: Celta, 1999.

BERTONCELLO, R. Configuración socioespacial de los balnearios del Partido de la Costa (Provincia de Buenos Aires). Territorio, Buenos Aires:Instituto de Geografía, Facultad de Filosofia y Letras, Universidad de Buenos Aires, 1993.

\section{DURKHEIM, E. Da divisão do trabalho} social. São Paulo: Martins Fontes, 1995[1893].
FERRARA, L. D. O turismo dos deslocamentos virtuais. In: YÁZIGI, E.; CARLOS, A. F. A.; CRUZ, R. C. A. (Orgs.). Turismo: espaço, paisagem e cultura. São Paulo: Hucitec, 1996. p. 15-24.

FRIEDMANN, G. 7 estudos sobre o homem e a técnica. São Paulo: Difusão Europeia do Livro, 1968.

FUINI, L. L. A relação entre competitividade e território no "Circuito das Malhas" do sul de Minas. Dissertação (Mestrado) Instituto de Geociências e Ciências Exatas, Universidade Estadual Paulista, Rio Claro, 2006.

PANORAMA SETORIAL. Gazeta Mercantil, São Paulo, 1997.

LANGENBUCH, J. R. Os municípios turísticos do estado de São Paulo: 
determinação e caracterização geral. Geografia, São Paulo: Associação dos Geógrafos Brasileiros, ano 2, n. 3, p. 1-49, abr. 1977.

MARX, K. O capital: crítica da economia política, v. 1. Livro Primeiro. O processo de produção do capital. São Paulo: Abril Cultural, 1983[1867]. Capítulo XII.

MORAES, R. B. Contribuições para a história do povoamento de S. Paulo até fins do século XVIII. Geografia, São Paulo: Associação dos Geógrafos Brasileiros, ano I, n. 1, p. 69-87, 1935.

MOURÃO, B. M. As águas minerais e as termas. São Paulo: Abinam, 1997.

NUNES, E.; LIMENA, M. M. C.; BORELLI, S. H. S. (Coorda.). Resultados da primeira fase da pesquisa " $A$ importância socioeconômica e cultural da água mineral no Brasil", jun./ago. 1999. São Paulo, 1999.

\section{SANTOS, M. Projeto de pesquisa:} empresas territoriais e dinâmicas da formação socioespacial brasileira. CNPq/Fapesp, 1998.

- A natureza do espaço: técnica e tempo, razão e emoção. São Paulo: Hucitec, 1996.

. O retorno do território. In: SOUZA, M. A. A.; SILVEIRA, M. L. (Orgs.). Território: globalização e fragmentação. São Paulo: Hucitec/Anpur, 1994a. p. 15-20.

\section{. Técnica, espaço, tempo:}

globalização e meio técnico-científicoinformacional. São Paulo: Hucitec, 1994b.

. O espaço: sistema de objetos, sistemas de ações. In: ENCONTRO NACIONAL DA ANPUR, 4., 1991, Salvador. Anais... Salvador, 1991. p. 35-39.
. Espaço e método. 3. ed. São Paulo: Nobel, 1985.

; RIBEIRO, A. C. T. O conceito de região concentrada.

UFRJ/Ippur/Departamento de Geografia, 1979. (Mimeo.)

; SILVEIRA, M. L. O Brasil: território e sociedade no início do século XXI. Rio de Janeiro: Record, 2001.

SANTOS, W. Cidades locais, contexto regional e urbanização no período técnico-científico: o exemplo da região de Campinas-SP. Tese (Doutorado em Geografia) Faculdade de Filosofia, Letras e Ciências Humanas, Universidade de São Paulo, São Paulo, 1989.

SILVEIRA, J. D. Estudo geográfico dos contrafortes ocidentais da Mantiqueira. Tese (Doutorado) Faculdade de Filosofia, Letras e Ciências Humanas, Universidade de São Paulo, São Paulo, 1946.

SILVEIRA, M. L. O espaço da globalização: usos diversos, comando único. In: SOUZA, A. J. et al. (Orgs.). Milton Santos: cidadania e globalização. São Paulo/Bauru: Saraiva/AGB, 2000. p. 121-127.

Da fetichização dos lugares à produção local do turismo. In: RODRIGUES, A. P. B. (Org.). Turismo, modernidade, globalização. São Paulo: Hucitec, 1997. p. 36-45.

SILVESTRE, V. Enfoque geográfico de um espaço turístico: um olhar sobre São Lourenço (MG). Tese (Doutorado em Geografia) - Faculdade de Filosofia, Letras e Ciências Humanas, Universidade de São Paulo, São Paulo, 1995.

SUMÁRIO MINERAL. Brasília:Departamento Nacional de Produção Mineral, 2001/2002. 